\title{
Research on Low Ambient Short-circuit Test and X-Ray Inspection for Inner Damage of Single Encapsulation Dual Winding Reactor Models
}

\author{
DU Haoyang ${ }^{1, \mathrm{a}}$,AO Ming ${ }^{1, \mathrm{~b}}$, SHI Dongyun ${ }^{1, \mathrm{c}}$, ZHAO Chunming ${ }^{1, \mathrm{~d}}$ WANG \\ Shijiu, ${ }^{2, e}$, XIAO Zhongjin ${ }^{3, f}$ \\ ${ }^{1}$ State Grid Jilin Electric Power Research Institute, No.4433 Renmin Street, Changchun, Jilin \\ 130021, China \\ ${ }^{2}$ Shanghai Power Transmission and Distribution Engineering, Company, No.239 Wuzhong Road, \\ 200235, Shanghai, China \\ ${ }^{3}$ State Grid Wuhan Power Supply Company, Wuchang District, Wuhan, 430000, China

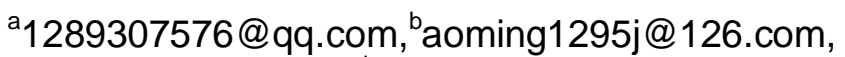 \\ c459568477@qq.com, ${ }^{\mathrm{d}}$ zhaochunming-26@163.com, \\ eWangshj@sh.sgcc.com.cn, ${ }^{\mathrm{e} X i a o c h j @ h b . s g c c . c o m . c n}$
}

Keywords: dry-type reactor, low ambient short circuit destroy test, inner damage, X-ray inspection Abstract. Low ambient temperature destroys of dry-type air ore reactors often occurred in recent years. In this paper, single encapsulation dual winding reactor models have been prepared. X-Ray inspection has been performed for inner damage examination after destroy by short-circuit under lowambient electrifying. A new evaluation method has been proposed for the inner defect examination of dry type reactors.

\section{Introduction}

Low ambient temperature damage of dry-type air core reactors often occurred in recent years. Failure analyses and related examinations had been carried out [1-3]. Researchers from Harbin University of Science and Technology have pointed out that the quick winds temperature decreasing will cause big temperature difference which induces larger expansion and stress. The stress will induce cracks in encapsulation, which may effected by the circumstance rain, humidity, bird droppings, which may cause inter-turn short circuit fault., even the burn-out of reactors. Most evaluations nowadays are focused on insulation and charging, few work has been carried out on the inner damage of reactors. An X-ray inspection method has been proposed based on low-ambient temperature short-circuit test.

\section{Low-ambient temperature short-circuiting Test}

Single encapsulation dual winding reactor models have been prepared for the test of low -ambient temperature short-circuiting test. The size of the model is $\Phi 200 \times 450 \mathrm{~mm}$ with $2 \mathrm{~mm}$ copper wires inside. The test has been carried out in the National Key laboratory of Dielectric and its Application in Harbin University of Science and Technology. The test temperatures are $-25^{\circ} \mathrm{C},-40^{\circ} \mathrm{Cand}-50^{\circ} \mathrm{C}$. Different circuit has been electrified on reactor models. Surface temperature increasing and winding temperature increasing have been monitored. Short-circuit occurred in reactor model 1 under $-60^{\circ} \mathrm{C}$ with 70 amperes for 26 minutes. After 65A for 30minutes, no destroy occurred for reactor model 2. Then cool the model to $-50^{\circ} \mathrm{C}$ with 65 amperes for 23 minute, short circuit occurred on this model. According to the temperature measuring results, the highest temperature increasing points locate in the $3 / 8$ height from the top end. 


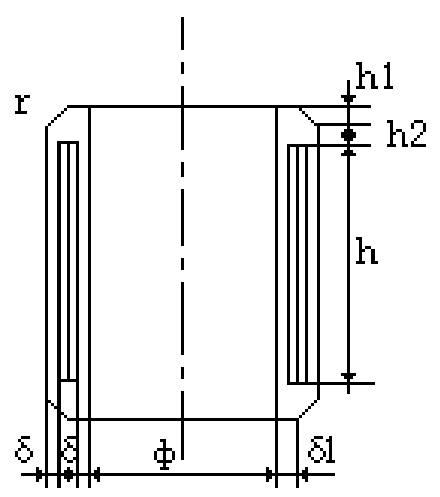

1 Copper wire $\Phi 2.0 \mathrm{~mm}$

$2 \mathrm{~h}=400 \mathrm{~mm} . \mathrm{h} 1=\mathrm{h} 2=10 \mathrm{~mm}, \Phi=200 \mathrm{~mm}, \delta=2.0 \mathrm{~mm}, \delta 1=4.0 \mathrm{~mm}$

3 Inner lining $0.5 \mathrm{~mm}$ metal sheet

4 Inner winding group left, outer winding group right;

5 Two winding group induced separately with $100 \mathrm{~mm}$ binding clips

6 Cross bus-bar installed on the two ends of the model

7 prepared according to regular procedures

8 Quantity 5

Fig. 1 Single encapsulation reactor model

\section{X-Ray inspection for the inner defects of reactor after short-circuit}

$\mathrm{X}$-Ray inspection has been carried out for the inner damage of the reactor after short circuit. Further dissembling has been performed to verify the short-circuit position. Testing facilities and materials include WX-2003 circumstantial X-Ray detector, Tianjin-III Type film, developer, fixer, image quality indicator, timer, view-box. Fig. 2 shows the layout of X-Ray detector and the reactor to be inspected.

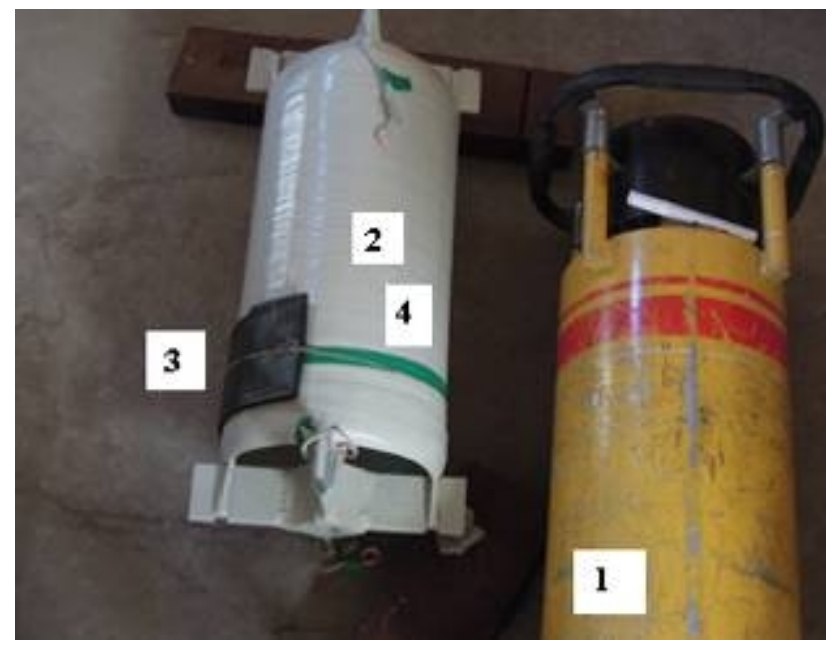

$1 \mathrm{X}$-ray detector

2 Reactor for inspection

3 Film

4 Marked area for inspection

Fig. 2 Layout of X-Ray detector, reactor and film

$\mathrm{X}$-ray detection is a traditional non-destructive method for the inspection of the inner damages and defects of metal materials. We tried to apply this technique on the inspection of the inner damage and deformation of the reactor. No work has been carried out before. The inspection is carried out in Jilin Electric Power Boiler and Pressure Vessel Examination Center. According to the resistance measuring result, the suspected short-circuit area has been marked by green shown in fig.2. X-Ray examination will be performed along the circumferential part. According to the length and test requirement, 3 positions have been exposed along the circus to cover the total suspected area, refer to fig.3.Table 1 show the $\mathrm{X}$-Ray exposure parameters. 


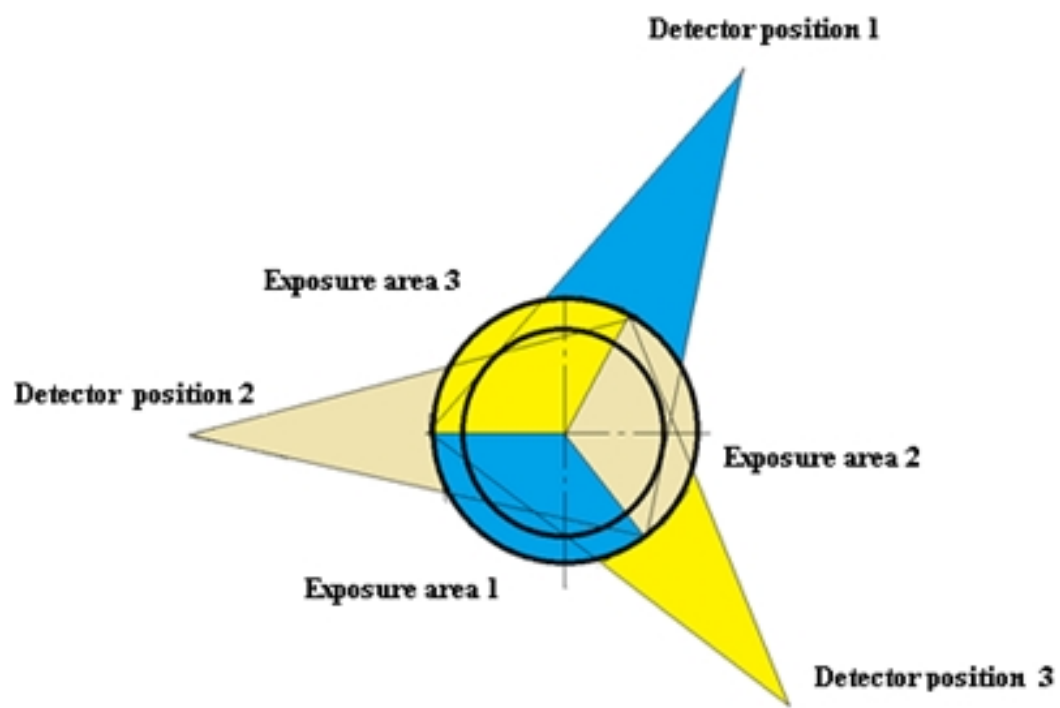

Fig.3 Indication of X-Ray exposure positions

Table 1 X-Ray inspection parameters

\begin{tabular}{|c|c|c|c|c|c|c|}
\hline Materials & Epoxy+w & jire & $\begin{array}{l}\text { Nominal } \\
\text { thickness }\end{array}$ & $2 \mathrm{~mm}$ & Ref. Codes & JB4730.2-2015 \\
\hline \multirow{4}{*}{$\begin{array}{l}\text { Detect } \\
\text { Conditions }\end{array}$} & $\begin{array}{l}\text { Detector } \\
\text { Type }\end{array}$ & WX2003 & $\begin{array}{l}\text { Intensifying } \\
\text { Method }\end{array}$ & Lead Foil & Penetrometer & - \\
\hline & $\begin{array}{l}\text { Indicator } \\
\text { Number }\end{array}$ & 13 & Voltage & $170 \mathrm{Kv}$ & Current & $5 \mathrm{~mA}$ \\
\hline & $\begin{array}{l}\text { Film } \\
\text { Type }\end{array}$ & T-III & $\begin{array}{l}\text { Exposure } \\
\text { Method }\end{array}$ & DWSS & $\begin{array}{l}\text { Exposure } \\
\text { Length }\end{array}$ & $1.0 \mathrm{~min}$ \\
\hline & $\begin{array}{l}\text { Film } \\
\text { Length }\end{array}$ & $300 \mathrm{~mm}$ & Focus length & $600 \mathrm{~mm}$ & Darkness & $2.0-3.0$ \\
\hline
\end{tabular}

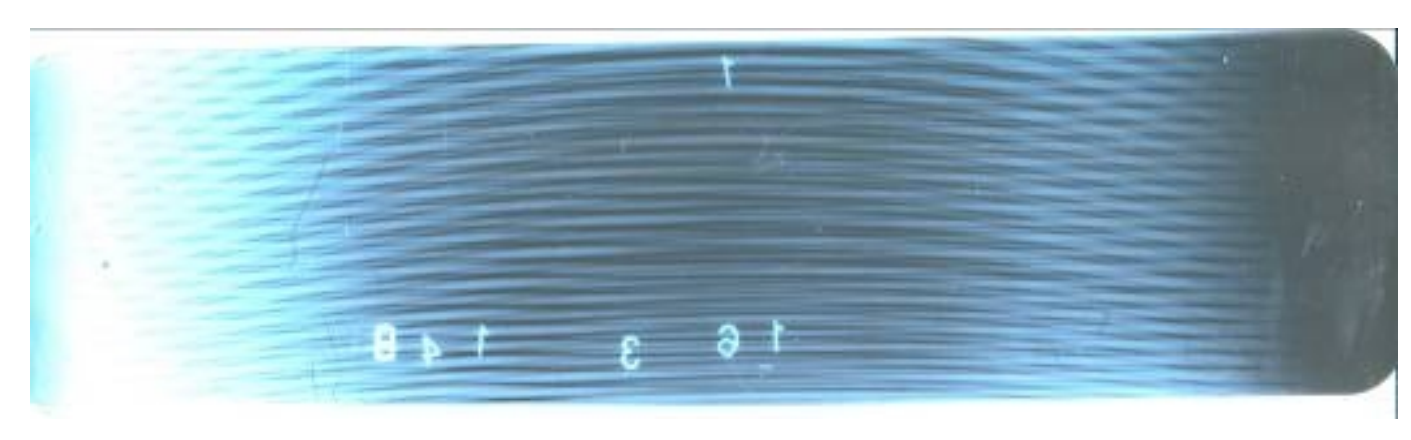

Fig.4 X-Ray inspection image on negative

\section{Damage Verification by Disassembly}

In order to verify the short-circuit position and other damage, one of the damaged reactor has been selected to disassembly for further observation. Fig. 5 shows the short circuit position and discharge trace. No obvious deformation could be found, which is in accordance with the X-ray inspection. 

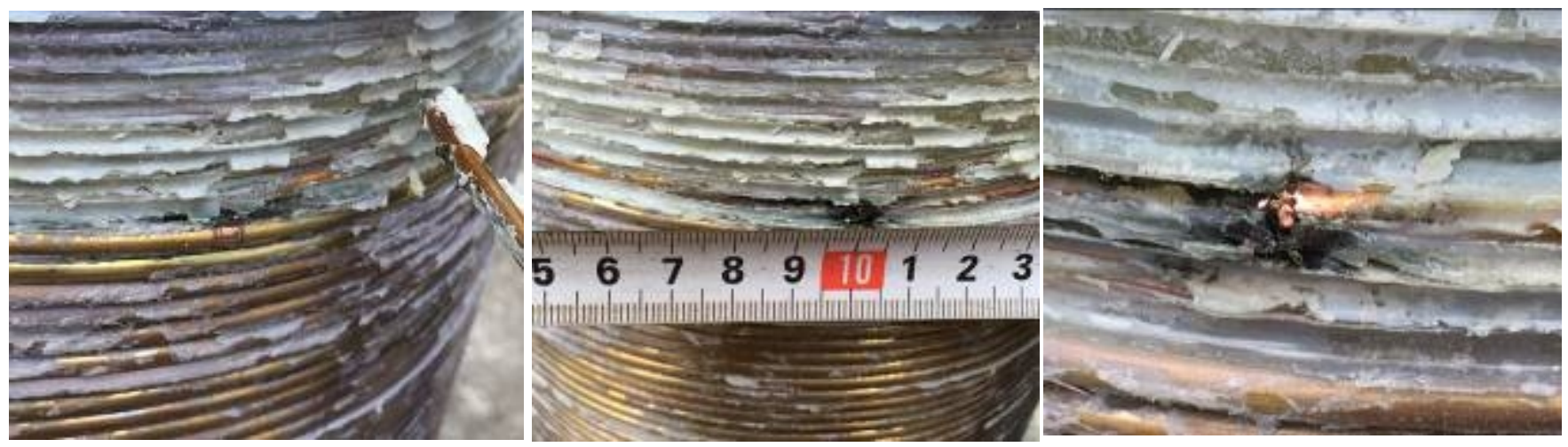

Fig.5 Short circuit position and discharge trace

\section{Analyses}

1 No cracks, abnormal deformation have been found on inner winding by observing on the X-Ray negatives;

2 No cracking, abnormal deformation has been found on epoxy resin by observing on the X-Ray negatives;

3 No cracking, abnormal deformation has been found on inner winding by dissembling, which is in according with the X-Ray inspection;

4 Discharging point and partial melting, insulation destroy have been observed by dissembling;

5 The defects including Discharging point and partial melting, insulation destroy could not be observed by X- Ray inspection.

\section{Future Suggestions}

It could be concluded that tiny deformation and damage could not be observed by the procedure adopted in this paper. The following methods could be tried to improve the accuracy of X-Ray inspection.

1 Adjusting the exposure method from the side exposure into front exposure, to find out the short circuiting and radius cracking of the encapsulation;

2 Exposure the same position before and after low temperature test for comparison;

3 Adjusting X-Ray detecting procedures by multiple trials based on combinations of single wire, multiple wires, no deformation, tine deformation, single epoxy resin layer and multiple epoxy resin layer, try to optimize the suitable inspection procedure;

4 Adopting eddy current examination to detect the potential short circuit position and breaking position by measuring the change of electro-magnetic field.

\section{References}

[1] Xu Linfeng, Lin Yifeng, Wang Yonghong, Wei Xinlao, Chen Qingguo. Technique Research on Turn-to turn Overvoltage Test for Dry-type Air Core Reactors[J].High Voltage Apparatus.2012(7) : 1601-1609

[2] Xu Linfeng. Fault Analysis of Dry-type Air-core Series Reactor [J].Power Capacitor \&Reactive Compensation 2008(2)

[3] Wang Yongyong, Wen Xianglong, Liu Hua, Liu Jianjun. Burn -out of dry hollow parallel reactors [J].Heilongjiang Electric Power, 2003(6) 